This item was submitted to Loughborough's Research Repository by the author.

Items in Figshare are protected by copyright, with all rights reserved, unless otherwise indicated.

\title{
latrogenic menopause after treatment for cervical cancer
}

\section{PLEASE CITE THE PUBLISHED VERSION}

http://dx.doi.org/10.1016/j.clon.2016.08.016

\section{PUBLISHER}

(c) Published by Elsevier Ltd on behalf of The Royal College of Radiologists.

\section{VERSION}

AM (Accepted Manuscript)

\section{PUBLISHER STATEMENT}

This work is made available according to the conditions of the Creative Commons Attribution-NonCommercialNoDerivatives 4.0 International (CC BY-NC-ND 4.0) licence. Full details of this licence are available at: https://creativecommons.org/licenses/by-nc-nd/4.0/

\section{LICENCE}

CC BY-NC-ND 4.0

\section{REPOSITORY RECORD}

Moss, E.L., S. Taneja, Fehmidah Munir, C. Kent, L. Robinson, N. Potdar, P. Sarhanis, and Hilary McDermott. 2019. "latrogenic Menopause After Treatment for Cervical Cancer". figshare.

https://hdl.handle.net/2134/23447. 


\section{IATROGENIC MENOPAUSE FOLLOWING TREATMENT FOR CERVICAL}

\section{CANCER}

${ }^{1}$ EL Moss, ${ }^{1} \mathrm{~S}$ Taneja, ${ }^{2} \mathrm{~F}$ Munir, ${ }^{1} \mathrm{C}$ Kent, ${ }^{3} \mathrm{~L}$ Robinson, ${ }^{1} \mathrm{~N}$ Potdar, ${ }^{4} \mathrm{P}$ Sarhanis, ${ }^{2} \mathrm{H}$ McDermott

${ }^{1}$ Univeristy Hospitals of Leicester, Leicester, UK

${ }^{2}$ Loughborough University, UK

${ }^{3}$ Birmingham Women’s Hospital, Birmingham, UK

${ }^{4}$ London North West Healthcare NHS Trust, UK

Address for correspondence: Dr Esther Moss, Department of Cancer Studies, University of Leicester, Leicester Royal Infirmary, Leicester, LE2 7LX. Email: em321@le.ac.uk. Tel: 0044 2584861

\section{HIGHLIGHTS:}

- Treatment for cervical cancer can result in an iatrogenic menopause.

- Iatrogenic menopause is associated with long-term morbidity and mortality.

- HRT can reduce these effects although compliance with treatment is a major challenge

- Non-HRT based interventions are needed for women who chose not to take HRT

KEY WORDS: Cervical Cancer; iatrogenic menopause; premature ovarian failure; radiotherapy; hormone replacement therapy 


\section{INTRODUCTION}

Cervical cancer is typically a disease of young women with the incidence in the UK being highest amongst women aged 25 to 29 years (19.3/100,000 women) [1]. Many of women diagnosed with a cervical cancer will have early stage, microscopic disease (stage IA) and will be successfully treated with local excision, thereby preserving their fertility and ovarian function. However, data from the NHS Cervical Screening Programme (NHSCSP) Audit of Invasive Cervical Cancer 2009-2013 document [1] reports that $67.7 \%$ of women under 25 years and $53.1 \%$ of women $25-49$ years had at least stage IB disease at diagnosis, which would result in loss of fertility and iatrogenic menopause in the majority of cases either due a bilateral oophorectomy as part of a hysterectomy, or chemoradiotherapy as either as primary or adjuvant treatment. Although cervical cancer accounts for only $1 \%$ of cancer cases in the UK, the issue of iatrogenic menopause as a consequence of treatment for cervical cancer, given the age distribution of the cases, is not inconsiderable and the number of women affected is increasing year on year.

The improvement in the prognosis of women diagnosed with a cervical cancer as a result of the addition of concomitant chemotherapy to radiotherapy [2] has meant that survivorship and treatment-related sequelae are being brought more into the spotlight in an attempt to try reduce morbidity and improve women's long-term health. The aim of this article is to review the issues surrounding iatrogenic menopause in cervical cancer, potential management options and barriers to treatment. Other malignancies that require pelvic radiotherapy can also result in ovarian failure and many of the issues that effect cervical cancer patients can be extrapolated to them, although the risks and management would need to be determined on an individual basis. 


\section{PREMATURE OVARIAN FAILURE}

The management of an early menopause should have two goals, firstly to alleviate the woman's symptoms, typically vasomotor and mood disorders, and secondly to reduce the risk of the long-term health consequences, which can result from hypoestrogenaemia, in particular the cardiovascular and bone effects. Women who have undergone premature ovarian failure (POF) due to oncological treatment are subject to a sudden onset of menopause which is often more severe than physiological menopause [3], with the onset of symptoms within days of surgery and within 12 weeks after starting radiotherapy. The stress of undergoing a cancer diagnosis can also cause menopausal symptoms to become more severe [4].

\section{Cardiovascular disease}

POF can lead to earlier than expected serious health consequences contributing to increased morbidity and mortality even in women who have not had to undergo cancer treatment, including cardiovascular disease, osteoporosis, cognitive impairment, including dementia and parkinsonism, psychological effects, impaired sexual function and subfertility. Bilateral oophorectomy has been associated with increased cardiovascular risk and premature death with the younger the age at oophorectomy the greater the increase in risk [5]. In those with POF under the age of 40 , increased risk of mortality from ischaemic heart disease is up to $50 \%$ higher compared with those with a menopause at the age of 52-55 [6]. The underlying pathophysiology of this is likely to be hypoestrogenism contributing to enhanced progression of atherosclerosis $[7,8]$ and this risk can be reduced by commencing oestrogen replacement [9]. 


\section{$\underline{\text { Osteoporosis }}$}

One of the biggest risks of POF is osteoporosis and this is associated with a significantly elevated fracture risk and the morbidity that accompanies this [10]. Analysis of DEXA scans performed at diagnosis of POF show $3.6 \%$ of women have bone density within the osteoporotic range and $25.9 \%$ have osteopenia [11]. Oestrogen therapy is the most effective intervention for preventing bone loss in women with POF [11] and HRT, even low dose regimens, reduces the risk of osteoporosis and subsequent fractures [12, 13]. Additional measures, including regular weight-bearing exercise, a calcium-rich diet with consideration of calcium and vitamin D supplementation if deficient, have also been shown to be beneficial.

\section{$\underline{\text { Neurological and cognitive effects }}$}

There is evidence that women who have undergone an early menopause without oestrogen replacement have an increased risk of dementia or reduced cognitive function [14]. Evidence to date suggests that there may be a neuroprotective effect of oestrogen on the brain, and that the effect may be age-dependent $[15,16]$. Several observational studies have found that women who have used HRT after their menopause have better cognitive functions than controls $[17,18]$. However, women who choose to use HRT after the menopause have in general, higher education, healthier life-styles and are healthier before using HRT than women who do not [19] and therefore this may be a could be a confounding factor in trying to determine true causality [16]. Women with a premature surgical menopause also appear to have an increased risk of parkinsonism compared with controls and the risk is increased with younger age at oophorectomy [20]. 
Although HRT is advocated in the management and treatment of psychological and cognitive symptoms associated with the menopause [21] it is debatable whether depression is the direct result of the loss of oestrogen in menopausal women or arises as a result of other menopausal symptoms [22, 23]. Longitudinal studies indicate that mood symptoms may be a result of menopausal women experiencing vasomotor symptoms, sexual dysfunction and poor quality sleep [23-25] thereby impacting on their psychological wellbeing. However, a meta-analysis including studies that were mostly randomized controlled trials, concluded that HRT appears to be effective in reducing depressed mood among menopausal women (overall effect size for HRT was 0.68) [26].

\section{Sexual function}

Dyspareunia due to vaginal atrophy is a common and distressing consequence of POF and along with loss of libido can lead to significant sexual dysfunction. A systematic review of studies suggested that vaginal dryness, pain, bleeding and severe dyspareunia were all prominent issues of sexual dysfunction and that in terms of treatment modality, radiotherapy appears to be associated with worse quality of life and sexual function [27]. Pelvic radiation can lead to epithelial sloughing, ulcer formation and necrosis. This effect can progress on to vaginal wall thinning, adhesions, fibrosis and ultimately vaginal stenosis [28]. The bladder is similarly affected and therefore common symptoms are urgency and hemorrhagic cystitis.

The loss of ovarian function due to adjuvant therapy affects androgen secretion and therefore can lead to low libido. Psychological factors such as low self esteem and loss of fertility are also major contributory factors and cervical cancer survivors are at increased risk of developing sexual pain disorders [29]. The use of topical oestrogens (see Hormone Replacement Therapy and Cervical Cancer section) can help to alleviate these symptoms significantly. 


\section{POPULATION CHARACTERISTICS}

Women of screening age (25-64 years) diagnosed with a cervical cancer have been consistently shown to be less likely to attend when invited for routine cervical screening [1], and the proportion of cancers associated with non-compliance with the NHSCSP has increased significantly over the past two decades [30]. Failure to engage with a structured screening programme has been indentified as one of the major risk factors for developing a malignancy and this raises the concern that this population of women may continue this behavioural pattern after their diagnosis, being less likely to comply with treatment for their premature menopause. The reasons for such behaviour will of course be multi-factorial however it is known that the majority of women who develop a cervical cancer belong to the most deprived socioeconomic quintile [31], which raises the possibility that a lack of health education is a significant contributing factor. Social isolation and factors that result in a lack of engagement with health care, either due to alcohol abuse or a language barrier, have been shown to be associated with emergency routes of presentation for cervical cancer and advanced disease at diagnosis [32]. Smoking is also known to be more prevalent in the cervical cancer population as compared to the background population, which itself increases the risk of cardiovascular disease and osteoporosis.

\section{STRATEGIES FOR PRESERVING OVARIAN FUNCTION}

Ovarian tissue is very sensitive to radiation with doses of only 6-15Gy, depending on fractionation, leading to permanent ovarian failure [33]. In many cases of cervical cancer it will be necessary for the ovaries to be irradiated as part of treatment since the incidence of metastasis, although lower in squamous carcinomas, is considerably higher in adenocarcinomas, $2.17 \%$ compared with $9.85 \%$ for stage IIB tumours [34]. Long-term 
survival in women with ovarian metastasis is poor, 5-year survival of $46.6 \%$ for Stage IB and only $18.0 \%$ for Stage IIB, with a high distance relapse rate [34] and therefore it is important that women are appropriately selected and counselled if ovarian function is to be preserved.

In women with ovarian conservation, the determination of menopause and the decision to institute HRT is dependent primarily upon the menopausal symptoms (vasomotor symptoms, musculoskeletal symptoms, effects on mood, urogenital symptoms, reduced sexual desire). Further tests in the form of serum follicle-stimulating hormone (FSH) can be performed on two occasions at least four-six weeks apart to confirm the diagnosis of POF, however, it should be only used in women under 45 years of age [35]. Serum anti-Müllerian hormone (AMH) and antral follicle count by ultrasound scan are used to determine ovarian reserve for fertility treatment and are not recommended for diagnosis of premature menopause or menopause [35].

\section{Ovarian transposition}

Ovarian transposition, moving the ovaries out of the pelvic radiation field, has been used for half a century in order to preserve ovarian function in patients with pelvic malignancies requiring pelvic irradiation. Different surgical techniques have been developed with the minimal access route, laparoscopic or robotic, being favoured due to a shorter recovery time [36]. It is not a widely used technique since it is felt that even with modern radiotherapy techniques, such as IMRT, ovaries will still receive enough radiation to induce menopause. Most of the reports in the literature are case series from single institutions and include a selected population of young, premenopausal patients with stage IB-IIA cervical tumours with a need for primary or adjuvant radiotherapy. A systematic review and meta-analysis of the outcomes of ovarian transposition in gynaecological cancers found that it was associated with the preservation of ovarian function [37] and successful pregnancy outcomes have also been reported [38], however metastases in transposed ovaries and recurrence have been 
reported [39]. Although this technique would not be suitable for all and care must be taken with case selection since non-squamous histology, stage and unaffected peripheral stromal thickness have been shown to be significantly associated with an increased risk of recurrence [40], it may prevent the onset of menopause in a proportion of cases as well as opening up the possibility for oocyte retrieval and pregnancy through surrogacy [41].

\section{Ovarian tissue preservation}

There are various options available to young women with regard to preserving ovarian tissue for future fertility treatment. These include cryopreservation of embryos, mature and immature oocytes and of ovarian tissue. For post pubertal women all options are potentially available but for pre-pubertal girls or women for whom it is imperative to start cancer treatment immediately ovarian tissue cryopreservation is the only potential option.

Embryo freezing is a well established technique used routinely in IVF cycles and achieves a pregnancy rate of on average $30 \%$ [42]. It requires time for controlled ovarian hyperstimulation and egg collection, therefore potentially delaying the start of treatment by 23 weeks. It is also dependent upon the presence of a partner and stable relationship since the consent of both partners is required for the subsequent use of the embryos. Additionally, in the case of cervical cancer where the uterus will be irradiated, a surrogate will be needed in order to carry the pregnancy.

Oocyte cryopreservation is another option for single woman or those not in a stable relationship. Although the success rates are less than embryo cryopreservation, with the advancing cryopreservation techniques such as vitrification there is improvement in the 
pregnancy rates achieved by this procedure [43]. Similar to embryo cryopreservation it requires time for controlled ovarian hyperstimulation and egg collection.

Ovarian tissue preservation is an evolving technique provided by very few centres in the UK and within research context. While only 24 live births have occurred worldwide as a result of this treatment, with the increasing survival from childhood malignancy and women's expectation of fertility preservation it seems likely to become an established option. The issue of the quantity of ovarian cortex to be removed, strips of cortex [44] or even the whole ovary [45], needs to be decided upon in accordance with the type of cancer treatment planned, the potential for metastatic dissemination and the risk of premature ovarian failure. Once the patient has recovered from their treatment and is disease free the ovarian tissue can be reimplanted, either in the pelvis (orthotopic) or at a distant site (heterotopic). Pelvic implantation to date has either been onto the remaining ovary (if present) by removing a piece of cortex to expose the medulla and allow a site of angiogenesis [46, 47], or using a two stage procedure a peritoneal window is made in the broad ligament and a vascular bed created before reimplanting tissue [48]. These techniques may not be possible after treatment for cervical cancer due to the effect of radiotherapy on the vasculature, thereby favouring a heterotopic site, the most common being the abdomen or forearm, but there are no pregnancies to date using this technique. There is consistent evidence that ovarian function is restored using heterotopic transplantation and has an expected duration of function of 4-5 years [46, 49-51]. It also has the advantages of avoiding invasive procedures, easy recovery of oocytes, and avoidance of injury in patients with severe pelvic adhesions [50-52]. In order to reduce the risk of tumour recurrence, techniques such as vitro maturation of oocytes from ovarian tissue or transplantation of isolated primordial follicles on an alginate gel matrix are being developed and are possible options for the future [53]. 


\section{$\underline{\text { Ovarian sparing radiotherapy techniques }}$}

Advanced intensity modulated radiotherapy (IMRT) techniques (such as RapidArc, Tomotherapy and Volumetric Arc therapy) are being rapidly adopted by UK radiotherapy centres for the chemoradiotherapy treatment of cervical cancer. Such techniques have dosimetric benefits and the ability to create sharp dose gradients and limit the total dose received by certain organs at risk. Ovarian preservation with IMRT techniques is technically challenging due to the poor visualisation of the ovaries at the time of planning and that they are inevitably incorporated into the high dose clinical target volume (CTV). Ovarian transposition prior to chemoradiotherapy may result in a reduced dose to these structures provided that the ovaries are transposed away from the nodal planned target volume (PTV).

Current recommendations for IMRT treatment of cervical cancer recommend including the entire uterus within the CTV since there is no clear fascial plane separating the cervix and both structures contain continuous lymphatics. Whether to include the whole uterus however remains a controversial topic amongst experts since trachelectomy for early stage disease has opened up a fertility sparing option. It must be noted that patients treated with chemoradiotherapy typically have more advanced disease and therefore such benefits are unlikely to be translated into this group. Caution must therefore be exercised in such cases and patients enrolled into clinical trials where available.

\section{HORMONE REPLACEMENT THERAPY AND CERVICAL CANCER}

Cervical cancer is not a hormone dependant cancer although a number of studies have shown that oestrogen and progesterone receptors are found in the cervix and in a proportion of tumours [54-56]. Despite oestrogen and progesterone receptors being expressed in 39\% and $33 \%$ of adenocarcinomas [54], exogenous oestrogen has not to date been shown to be associated with an increased risk of developing squamous cell carcinoma when compared to 
HPV positive controls [56-58]. Several studies even noted a reduction in squamous cell carcinoma rates in women on HRT $[59,60]$, but this is likely to be because of increased screening compliance as a result of regular medical review.

The association between HRT and cervical adenocarcinoma is however less clear with two studies reporting a positive association [56, 59]. Jaakkola et al. [59], noted that risk was associated with duration of exposure with almost a 3 fold increase in risk after 10 years of use, although a causal mechanism for this remains to be identified and it is possible that the findings are as a result of confounding factors. Importantly neither oestrogen nor progesterone receptor expression have to date been shown to significantly influence diseasefree and overall survival in cervical adenocarcinomas [54] and several studies actually reported improved survival rates with expression [55, 61].

There is only one randomised, controlled trial in the literature investigating the effect on HRT on survival for women treated with radiotherapy alone or combined with surgery for a stage I/II cervical cancer [62]. No significant difference in cervical cancer recurrence or in overall survival was seen at the end of 5-years between women who took HRT and those who did not therefore women using HRT should be reassured that HRT does not appear to cause an increase in recurrence of cervical cancer.

Oestrogen containing HRT has been shown to be effective in managing menopausal symptoms after radiotherapy for cervical cancer with a reduced incidence of postradiotherapy complications [62]. Any complications that were present were milder and of shorter duration when compared with those women in the control group who did not receive HRT, $\mathrm{p}<0.01)[62]$. 
Topical oestrogens are highly effective at relieving urogenital symptoms related to vaginal atrophy [63]. There is minimal systemic absorption through the atrophic mucosa as studies have shown an initial rise in unconjugated plasma oestradiol but within two weeks of treatment this has declined to postmenopausal levels $[64,65]$. Other methods of improving sexual function are using water and oil based lubricants and if there is narrowing and shortening of the vagina, dilators may be helpful.

\section{HORMONE REPLACEMENT THERAPY REGIMENS}

\section{Route of delivery and Preparations}

There are many different HRT formulations and preparations, for example transdermal patch, transdermal gel, oral tablet and vaginal ring. The preparations may contain oestrogen only, a progesterone only or be a combination both hormones. The choice of preparation or combination of preparations will be dependent on the individual patient, on her individual clinical situation and her personal preferences.

The transdermal as compared to the oral route has several advantages [35]. In particular, it does not appear to increase the risk of venous thromboembolism (VTE) compared to a significant increase with oral oestrogens [35]. Also, the risk of ischaemic stroke is slightly increased with oral, but not transdermal oestrogen [35]. Transdermal HRT in the form of gel or patches are preferable in women where drug bioavailability may be affected by concomitant medication, for example drugs for epilepsy or migraine and have been shown to be more cost effective than oral HRT [35]. Absorption levels have been shown to vary with the transdermal route and local skin reactions to patch adhesives mean that some women may have to switch to oral preparations.

Although there are some combined transdermal preparations commercially available, the 
doses of oestrogen contained in them are sometimes not high enough to alleviate women's symptoms. Rather than increasing the dose of progesterone by giving two patches it is preferable as previously described to uncouple the two hormones to allow the dose of oestrogen to be titrated and using separate progesterone, such as medroxyprogesterone acetate or a micronized progesterone. This therefore avoids the need to increase the progesterone dose, and the adverse effects that are associated with it, for example bloating, mood changes, breast tenderness and skin problems. The type of progesterone can also be chosen depending on women's symptoms, C19 derived progestogens, for example norethisterone, are good for cycle control and reducing unscheduled bleeding, whereas the C21 derived progestogens, for example medroxyprogesterone acetate, dydrogesterone or micronized progesterone [66], are better for avoiding androgenic symptoms [67]. There is emerging evidence that micronized progesterones may be preferable with regard to breast cancer risk as compared to oral preparations [68] and they can be used orally or vaginally alongside transdermal or oral oestrogen-only preparations.

Subcutaneous oestrogen implants may be helpful in managing young patients who have severe symptoms. They are inserted every 5-6 months subcutaneously in the abdominal fat by a minor surgical procedure and appear to have a similar risk profile to transdermal oestrogens, although there is a risk of tachyphylaxis with prolonged use [69].

Low testosterone has been reported as a cause for low libido in women who have undergone POF. Transdermal testosterone gel or an implant have been used as treatments for this but they are currently unlicensed in women in the UK [35]. 


\section{Following hysterectomy}

In women who have undergone hysterectomy, oestrogen-only HRT can be instituted since they will not require a progesterone for endometrial protection.

\section{In women who have not had a hysterectomy}

Despite the endometrium being exposed to high doses (60+ Gy) of radiotherapy for cervical cancer, residual functional endometrium has been shown to persist after the completion of treatment $[70,71]$. This residual endometrium can be stimulated by exogenous oestrogens [72] and therefore oestrogen-only HRT is not advised [70] since oestrogen-only HRT is a known risk factor for an endometrial malignancy [73] and a continuous combined 'no bleed' regime would be suitable for this population.

\section{NON-HORMONAL THERAPIES}

High profile media reports about the safety of HRT use have left many women reluctant to consider HRT as a therapeutic option for menopausal symptoms and in addition, a proportion of women are prevented from using HRT for medical reasons [74]. As a consequence, many women are seeking to use complementary and alternative medicine, including nonpharmacological interventions, to alleviate symptoms associated with the menopause [75]. There are a myriad of non-hormonal therapies that have been used to treat menopausal symptoms however the majority are only supported by individual anecdotal reports and not by clinical trial evidence [76]. In general, reviews of alternative and complimentary nonhormonal therapies indicate that large randomized placebo controlled trials are lacking and these therapies are not as effective as oestrogen at controlling vasomotor symptoms. The fact that there is a $50 \%$ improvement in symptoms with placebo highlights the requirement for large robust blinded randomised trials [77]. 


\section{Dietary supplements}

There are many dietary supplements that report to have a positive effect on menopausal symptoms however, the quality and proportion of active ingredients in many of these overthe-counter preparations is not known and therefore the effects will vary depending on manufacturer and their cannot be guaranteed [35]. Drewe et al., have conducted a systematic review examining the extensive evidence for non-hormonal treatments for menopausal vasomotor symptoms in women following a cancer diagnosis [78]. The most common supplement are the Isoflavones, which are found naturally in the Fabaceae family of legumes, for example soybeans, alfalfa and mung bean sprouts and red clover blossom. Genistein and daidzein are the main isoflavones in soy and have been evaluated in different doses in a variety of placebo-controlled trials. The results ranged from a reduction in symptoms to no difference compared to placebo, in particular in four studies in women with a breast cancer diagnosis [79-82]. A meta-analysis of six studies did indicate a reduction in the vasomotor symptoms after $12-16$ weeks and 26 weeks of use, -0.97 (95\% CI -1.82 to -0.12 ) and -1.22 (95\%CI -2.02 to -0.42) [83]. Red clover contains the isoflavones formononetin and biochanin in addition to genistein and daidzein. A meta-analysis of their effect on the frequency of hot flushes showed no difference compared to placebo, -0.44 (95\% CI -1.47 to 0.58) [83]. Black cohosh (Cimicifuga racemosa) is derived from a member of the buttercup family. A number of randomised trials have been conducted and a meta-analysis by Beer et al., [78] identified a significant effect as compared to placebo, in contrast to a Cochrane review published in 2012 [84]. NICE guidance does include support for isoflavones and black cohosh in the treatment of vasomotor symptoms however, it does advise that women should be made aware that the safety of individual preparations is unknown and they may interact with other medication [35]. Vitamin E succinate has also been proposed as a treatment and although a reduction of 
the frequency of flashes has been seen the clinical impact appears to be minimal as compared to placebo $[85,86]$.

\section{Pharmacological treatments}

Serotonin-norepinephrine and Selective serotonin reuptake inhibitors (SNRIs/SSRIs), clonidine and gabapentin are often used to control vasomotor symptoms but clonidine is the only one of these products licensed for this use. NICE guidance states that non-hormonal therapies should not be offered as the first line option for the management of vasomotor symptoms [35]. Clonidine (up to $50 \mathrm{mg}$ TDS) has been the subject of a number of studies of varying quality. A meta-analysis of 4 trials demonstrated a benefit compared to placebo of $0.95(-1.44$ to -0.47$)$ for the 4 -week trials and $-1.63(-2.76$ to -0.50$)$ for the 8-week trials [83]. The SNRI most commonly used is venlafaxine, especially in breast cancer patients [87], since it has a weak/negligible effect on cytochrome P450 unlike other SNRIs, for example fluoxetine and paroxetine, which are strong inhibitors of this enzyme system [88] and therefore reduce the efficacy of concomitant medication, in particular tamoxifen and other chemotherapeutic agents [89]. Venlafaxine can significantly reduce hot flushes and sweats and is used in doses up to $75 \mathrm{mg}$ daily. A double-blind, placebo controlled trial of investigating venlafaxine and clonidine showed a significant reduction in hot flashes for both treatments compared to placebo [90]. The efficacy of venlafaxine has been shown to be not dissimilar to that of low-dose oral oestrogen, with a $48 \%$ reduction in the frequency of vasomotor symptoms compared to $53 \%$, and is well tolerated, patient satisfaction of $52 \%$ compared to $69 \%$ for estradiol [91]. Gabapetin, in doses up to $900 \mathrm{mg}$ per day, has been shown to reduce the frequency of flashes compared to placebo, $44-45 \%$ versus $15-29 \%$, however is associated with a high level of reported adverse events, $50 \%$ compared to $27.6 \%$ 
in the placebo group [92, 93].

\section{Non-pharmacological treatments}

There are limited clinical data on non-pharmacological treatments such as behavioral interventions, exercise and acupuncture. Acupuncture has been found to be less effective than oestrogen in management of hot flushes but more beneficial than placebo. In their review, Daley, Stokes-Lampard and MacArthur [94] identified several large observational studies that demonstrated associations between exercise and lower rates of vasomotor symptoms. However, several smaller observational studies showed no association between exercise, menopausal symptoms and quality of life outcomes [94]. There is no supporting evidence from randomized controlled trials for the causal role of exercise in reducing vasomotor symptoms [74] yet exercise has been shown to have a significantly positive effect on quality of life and psychological symptoms [95] and appears to reduce the loss of bone mineral density in POF [96].

For mood and psychological symptoms recent NICE guidance recommends the use of cognitive behavioural therapy (CBT). SNRIs and SSRIs have not been shown to be effective for mood disorders related to the menopause and are only indicated in women with clinical depression or anxiety disorders [35].

\section{BARRIERS TO HRT USE}

Women who have become menopausal under the age of 45 years as a result of cervical cancer are significantly less likely to start HRT or continue it long term as compared to those who have undergone a surgical menopause for a benign reason [97]. Everhov et al. [97], identified that less than $46 \%$ of women who would be expected to have started HRT were prescribed it 
at or near the recommended dose $(\geq 75 \%)$ and although women under 40 years were more likely to use HRT than women aged 40 to 45 years, $56 \%$ versus $33 \%$, the rates fell to $21 \%$ and $20 \%$ by 5 years following treatment. The reasons for such low HRT usage are likely to be multi-factorial and suggest a lack of awareness of the benefits of HRT following an iatrogenic menopause for cervical cancer both amongst the patient and their clinician.

\section{Second malignancies}

One of the main concerns raised with the prolonged use of HRT is the increased risk of breast cancer. The Women's Health Initiative (WHI) study, which included women aged 50 to 79 years, identified that combined oestrogen and progestin HRT increases the risk of incident breast cancer in healthy postmenopausal women [98]. A more recent study however recruiting women aged 45 to 58 years who have recently become postmenopausal and started on HRT appear to have a reduced risk of mortality with no increase in cancer, VTE or stoke risk [99]. The WHI study findings have been extrapolated by the media and general public to mean that HRT use at any age is associated with an increased breast cancer risk and consequentially this has had a dramatic on HRT usage [100], although the absolute risks and associations are poorly understood and the study actually demonstrated a drop in breast cancer risk with oestrogen only HRT use [101]. The evidence for women undergoing a premature menopause is that they do not have an increase breast cancer risk but should instead continue HRT until the age of the natural menopause [102]. The concern that HRT usage will increase the risk of breast cancer in the treated cervical cancer population is therefore not grounded and some studies have actually indentified a reduced risk in this population [103, 104], which is likely to be due to the effect of an early menopause. 
Cases of endometrial carcinoma following treatment for cervical cancer have been reported even without additional oestrogenic stimulation and therefore, although the risk is low, suspicious symptoms should always be investigated. The avoidance of oestrogen-only HRT does not appear to be followed in clinical practice with only half of HRT prescribed to this population containing a progestogenic component [97]. This may be due to a lack of awareness amongst clinicians of a potential association but does need to be considered especially in women with additional risk factors for developing an endometrial malignancy, in particular obesity.

Second malignancies have been reported following radical radiotherapy to the pelvis for cervical cancer [105] but the estimated excess of cases is low, a relative risk of 1.1 for developing a malignancy in tissues surrounding the cervix exposed to high radiation levels [106]. The risk does increase with time, Rodriguez identified that 35 years following radiotherapy treatment the risk of developing a colon cancer was higher in women who received radiotherapy compared to those that did not, $6.5 \%$ versus $2.5 \%$, and $3.7 \%$ versus 0.8\% for a rectal cancer [107]. Radiation-associated uterine malignancies are more likely to be of higher grade and stage as compared to spontaneous cancers and as a result carry a poorer prognosis [108]. Several studies have identified an increased association with a second primary lung malignancy [104, 109], however this is likely to be a reflection of the smoking behaviour in this population and reinforces the importance of smoking cessation advice and support following a cervical cancer diagnosis. 


\section{Medical professionals}

Another potential barrier to HRT usage in this population is a lack of understanding as to the long-term implications of POF and the role of HRT following cervical cancer treatment by the medical team. Oncologists have their focus primarily on achieving the greatest survival with the lowest treatment-associated morbidity and there may be a role for specialist gynaecological endocrinology input in order to optimise POF management. There is also the challenge of ensuring that women continue with HRT following discharge from routine hospital follow up, typically after 5 years, since general practitioners will be unfamiliar with such prolonged HRT use, up to the age 50 years, and be under the misconception that this results in an increased breast cancer risk.

\section{CONCLUSIONS/RECOMMENDATIONS}

Iatrogenic menopause as a result of treatment for cervical cancer is associated with significantly increased long-term morbidity and mortality. The benefits of HRT in this population have been shown to reduce these effects although adherence to treatment regimens is a challenge due to poor compliance, which is in part due to fear of a second malignancy. The development of non-HRT based interventions to ameliorate menopausal symptoms and reduce the long-term health consequences are needed for women who chose not to take HRT.

\section{CONFLICT OF INTEREST}

None

\section{FUNDING}

None 


\section{REFERENCES}

1. NHSCSP. NHSCSP audit of invasive cervical cancer: National report 2009-2013. In; 2014.

2. Green J, Kirwan J, Tierney J, Vale C, Symonds P, Fresco L, et al. Concomitant chemotherapy and radiation therapy for cancer of the uterine cervix. Cochrane Database Syst Rev 2005:CD002225.

3. Ibeanu O, Modesitt SC, Ducie J, von Gruenigen V, Agueh M, Fader AN. Hormone replacement therapy in gynecologic cancer survivors: why not? Gynecol Oncol 2011,122:447-454.

4. Hinds L, Price J. Menopause, hormone replacement and gynaecological cancers. Menopause Int 2010,16:89-93.

5. Lobo RA. Surgical menopause and cardiovascular risks. Menopause 2007,14:562566.

6. Jacobsen BK, Knutsen SF, Fraser GE. Age at natural menopause and total mortality and mortality from ischemic heart disease: the Adventist Health Study. J Clin Epidemiol 1999,52:303-307.

7. Clarkson TB. Estrogen effects on arteries vary with stage of reproductive life and extent of subclinical atherosclerosis progression. Menopause 2007,14:373-384.

8. Bairey Merz CN, Johnson BD, Sharaf BL, Bittner V, Berga SL, Braunstein GD, et al. Hypoestrogenemia of hypothalamic origin and coronary artery disease in premenopausal women: a report from the NHLBI-sponsored WISE study. J Am Coll Cardiol 2003,41:413-419.

9. Dubey RK, Imthurn B, Barton M, Jackson EK. Vascular consequences of menopause and hormone therapy: importance of timing of treatment and type of estrogen. Cardiovasc Res 2005,66:295-306.

10. van Der Voort DJ, van Der Weijer PH, Barentsen R. Early menopause: increased fracture risk at older age. Osteoporos Int 2003,14:525-530.

11. Maclaran K, Horner E, Panay N. Premature ovarian failure: long-term sequelae. Menopause Int 2010,16:38-41.

12. MacLean C, Newberry S, Maglione M, McMahon M, Ranganath V, Suttorp M, et al. Systematic review: comparative effectiveness of treatments to prevent fractures in men and women with low bone density or osteoporosis. Ann Intern Med 2008,148:197-213.

13. Gallagher JC. Moderation of the daily dose of HRT: prevention of osteoporosis. Maturitas 1999,33 Suppl 1:S57-63.

14. Rocca WA, Bower JH, Maraganore DM, Ahlskog JE, Grossardt BR, de Andrade M, et al. Increased risk of cognitive impairment or dementia in women who underwent oophorectomy before menopause. Neurology 2007,69:1074-1083.

15. Rocca WA, Grossardt BR, Maraganore DM. The long-term effects of oophorectomy on cognitive and motor aging are age dependent. Neurodegener Dis 2008,5:257-260.

16. Hogervorst E, Yaffe K, Richards M, Huppert F. Hormone replacement therapy for cognitive function in postmenopausal women. Cochrane Database Syst Rev 2002:CD003122.

17. Hogervorst E, Williams J, Budge M, Riedel W, Jolles J. The nature of the effect of female gonadal hormone replacement therapy on cognitive function in postmenopausal women: a meta-analysis. Neuroscience 2000,101:485-512.

18. Yaffe K, Sawaya G, Lieberburg I, Grady D. Estrogen therapy in postmenopausal women: effects on cognitive function and dementia. JAMA 1998,279:688-695. 
19. Matthews KA, Kuller LH, Wing RR, Meilahn EN, Plantinga P. Prior to use of estrogen replacement therapy, are users healthier than nonusers? Am J Epidemiol 1996,143:971-978.

20. Rocca WA, Bower JH, Maraganore DM, Ahlskog JE, Grossardt BR, de Andrade M, et al. Increased risk of parkinsonism in women who underwent oophorectomy before menopause. Neurology 2008,70:200-209.

21. Shah S, Harris TJ, Cook DG. Differences in hormone replacement therapy use by social class, region and psychological symptoms. BJOG 2001,108:269-275.

22. Avis NE, Crawford S, Stellato R, Longcope C. Longitudinal study of hormone levels and depression among women transitioning through menopause. Climacteric 2001,4:243-249.

23. Hickey M, Davis SR, Sturdee DW. Treatment of menopausal symptoms: what shall we do now? Lancet 2005,366:409-421.

24. Khan SA, Pace JE, Cox ML, Gau DW, Cox SA, Hodkinson HM. Climacteric symptoms in healthy middle-aged women. Br J Clin Pract 1994,48:240-242.

25. Dennerstein L, Guthrie JR, Clark M, Lehert P, Henderson VW. A population-based study of depressed mood in middle-aged, Australian-born women. Menopause 2004,11:563-568.

26. Zweifel JE, O'Brien WH. A meta-analysis of the effect of hormone replacement therapy upon depressed mood. Psychoneuroendocrinology 1997,22:189-212.

27. Ye S, Yang J, Cao D, Lang J, Shen K. A systematic review of quality of life and sexual function of patients with cervical cancer after treatment. Int J Gynecol Cancer 2014,24:1146-1157.

28. Jensen PT, Froeding LP. Pelvic radiotherapy and sexual function in women. Transl Androl Urol 2015,4:186-205.

29. Lammerink EA, de Bock GH, Pras E, Reyners AK, Mourits MJ. Sexual functioning of cervical cancer survivors: a review with a female perspective. Maturitas 2012,72:296-304.

30. Moss E, Askew S, Pearmain P, Jones P, Dawson P, Redman C. Is the screening behaviour of women diagnosed with a cervical cancer changing?

31. Brookfield KF, Cheung MC, Lucci J, Fleming LE, Koniaris LG. Disparities in survival among women with invasive cervical cancer: a problem of access to care. Cancer 2009,115:166-178.

32. Myriokefalitaki E, Potdar N, Barnfield L, Davies Q, Moss E. Cervical cancer still presents symptomatically 20 years after the introduction of a structured national screening programme. Cytopathology 2016.

33. Wallace WH, Thomson AB, Kelsey TW. The radiosensitivity of the human oocyte. Hum Reprod 2003,18:117-121.

34. Shimada M, Kigawa J, Nishimura R, Yamaguchi S, Kuzuya K, Nakanishi T, et al. Ovarian metastasis in carcinoma of the uterine cervix. Gynecol Oncol 2006,101:234237.

35. National Institute for Health Care Excellence. Menopause: diagnosis and management. 2015 https://www.nice.org.uk/guidance/ng23/resources/menopausediagnosis-and-management-1837330217413

36. Clough KB, Goffinet F, Labib A, Renolleau C, Campana F, de la Rochefordiere A, et al. Laparoscopic unilateral ovarian transposition prior to irradiation: prospective study of 20 cases. Cancer 1996,77:2638-2645.

37. Gubbala K, Laios A, Gallos I, Pathiraja P, Haldar K, Ind T. Outcomes of ovarian transposition in gynaecological cancers; a systematic review and meta-analysis. $J$ Ovarian Res 2014,7:69. 
38. Morice P, Thiam-Ba R, Castaigne D, Haie-Meder C, Gerbaulet A, Pautier P, et al. Fertility results after ovarian transposition for pelvic malignancies treated by external irradiation or brachytherapy. Hum Reprod 1998,13:660-663.

39. Morice P, Haie-Meder C, Pautier P, Lhomme C, Castaigne D. Ovarian metastasis on transposed ovary in patients treated for squamous cell carcinoma of the uterine cervix: report of two cases and surgical implications. Gynecol Oncol 2001,83:605-607.

40. Landoni F, Zanagnolo V, Lovato-Diaz L, Maneo A, Rossi R, Gadducci A, et al. Ovarian metastases in early-stage cervical cancer (IA2-IIA): a multicenter retrospective study of 1965 patients (a Cooperative Task Force study). Int J Gynecol Cancer 2007,17:623-628.

41. Steigrad S, Hacker NF, Kolb B. In vitro fertilization surrogate pregnancy in a patient who underwent radical hysterectomy followed by ovarian transposition, lower abdominal wall radiotherapy, and chemotherapy. Fertil Steril 2005,83:1547-1549.

42. HFEA. In; 2013.

43. Potdar N, Gelbaya TA, Nardo LG. Oocyte vitrification in the 21st century and postwarming fertility outcomes: a systematic review and meta-analysis. Reprod Biomed Online 2014,29:159-176.

44. Anderson RA, Wallace WH, Baird DT. Ovarian cryopreservation for fertility preservation: indications and outcomes. Reproduction 2008,136:681-689.

45. Poirot CJ, Martelli H, Genestie C, Golmard JL, Valteau-Couanet D, Helardot P, et al. Feasibility of ovarian tissue cryopreservation for prepubertal females with cancer. Pediatr Blood Cancer 2007,49:74-78.

46. Donnez J, Silber S, Andersen CY, Demeestere I, Piver P, Meirow D, et al. Children born after autotransplantation of cryopreserved ovarian tissue. a review of 13 live births. Ann Med 2011,43:437-450.

47. Sanchez-Serrano M, Crespo J, Mirabet V, Cobo AC, Escriba MJ, Simon C, et al. Twins born after transplantation of ovarian cortical tissue and oocyte vitrification. Fertil Steril 2010,93:268 e211-263.

48. Donnez J, Dolmans MM, Demylle D, Jadoul P, Pirard C, Squifflet J, et al. Livebirth after orthotopic transplantation of cryopreserved ovarian tissue. Lancet 2004,364:1405-1410.

49. Donnez J, Jadoul P, Squifflet J, Van Langendonckt A, Donnez O, Van Eyck AS, et al. Ovarian tissue cryopreservation and transplantation in cancer patients. Best Pract Res Clin Obstet Gynaecol 2010,24:87-100.

50. Rodriguez-Wallberg KA, Oktay K. Recent advances in oocyte and ovarian tissue cryopreservation and transplantation. Best Pract Res Clin Obstet Gynaecol 2012,26:391-405.

51. Kim SS. Assessment of long term endocrine function after transplantation of frozenthawed human ovarian tissue to the heterotopic site: 10 year longitudinal follow-up study. J Assist Reprod Genet 2012,29:489-493.

52. Oktay K, Economos K, Kan M, Rucinski J, Veeck L, Rosenwaks Z. Endocrine function and oocyte retrieval after autologous transplantation of ovarian cortical strips to the forearm. JAMA 2001,286:1490-1493.

53. Vanacker J, Luyckx V, Dolmans MM, Des Rieux A, Jaeger J, Van Langendonckt A, et al. Transplantation of an alginate-matrigel matrix containing isolated ovarian cells: first step in developing a biodegradable scaffold to transplant isolated preantral follicles and ovarian cells. Biomaterials 2012,33:6079-6085.

54. Bodner K, Laubichler P, Kimberger O, Czerwenka K, Zeillinger R, Bodner-Adler B. Oestrogen and progesterone receptor expression in patients with adenocarcinoma of 
the uterine cervix and correlation with various clinicopathological parameters. Anticancer Res 2010,30:1341-1345.

55. Masood S, Rhatigan RM, Wilkinson EW, Barwick KW, Wilson WJ. Expression and prognostic significance of estrogen and progesterone receptors in adenocarcinoma of the uterine cervix. An immunocytochemical study. Cancer 1993,72:511-518.

56. Lacey JV, Jr., Brinton LA, Barnes WA, Gravitt PE, Greenberg MD, Hadjimichael OC, et al. Use of hormone replacement therapy and adenocarcinomas and squamous cell carcinomas of the uterine cervix. Gynecol Oncol 2000,77:149-154.

57. Schneider C, Jick SS, Meier CR. Risk of gynecological cancers in users of estradiol/dydrogesterone or other HRT preparations. Climacteric 2009,12:514-524.

58. Persson I, Yuen J, Bergkvist L, Schairer C. Cancer incidence and mortality in women receiving estrogen and estrogen-progestin replacement therapy--long-term follow-up of a Swedish cohort. Int J Cancer 1996,67:327-332.

59. Jaakkola S, Pukkala E, H KL, Ylikorkala O. Postmenopausal estradiol-progestagen therapy and risk for uterine cervical cancer. Int J Cancer 2012,131:E537-543.

60. Adami HO, Persson I, Hoover R, Schairer C, Bergkvist L. Risk of cancer in women receiving hormone replacement therapy. Int J Cancer 1989,44:833-839.

61. Ghandour FA, Attanoos R, Nahar K, Gee JW, Bigrigg A, Ismail SM. Immunocytochemical localization of oestrogen and progesterone receptors in primary adenocarcinoma of the cervix. Histopathology 1994,24:49-55.

62. Ploch E. Hormonal replacement therapy in patients after cervical cancer treatment. Gynecol Oncol 1987,26:169-177.

63. Suckling J, Lethaby A, Kennedy R. Local oestrogen for vaginal atrophy in postmenopausal women. Cochrane Database Syst Rev 2006:CD001500.

64. Nilsson K, Heimer G. Low-dose 17 beta-oestradiol during maintenance therapy--a pharmacokinetic and pharmacodynamic study. Maturitas 1995,21:33-38.

65. Nilsson K, Heimer G. Low-dose oestradiol in the treatment of urogenital oestrogen deficiency--a pharmacokinetic and pharmacodynamic study. Maturitas 1992,15:121127.

66. L'Hermite M. HRT optimization, using transdermal estradiol plus micronized progesterone, a safer HRT. Climacteric 2013,16 Suppl 1:44-53.

67. Sitruk-Ware R. Pharmacology of different progestogens: the special case of drospirenone. Climacteric 2005,8 Suppl 3:4-12.

68. Fournier A, Berrino F, Riboli E, Avenel V, Clavel-Chapelon F. Breast cancer risk in relation to different types of hormone replacement therapy in the E3N-EPIC cohort. Int J Cancer 2005,114:448-454.

69. Kapetanakis E, Dmowski WP, Auletta F, Scommegna A. Endocrine and clinical effects of estradiol and testosterone pellets used in long-term replacement therapy. Int J Gynaecol Obstet 1982,20:387-399.

70. Singh P, Oehler MK. Hormone replacement after gynaecological cancer. Maturitas 2010,65:190-197.

71. de Hullu JA, Pras E, Hollema H, van der Zee AG, Bogchelman DH, Mourits MJ. Presentations of endometrial activity after curative radiotherapy for cervical cancer. Maturitas 2005,51:172-176.

72. Ziel HK, Finkle WD. Increased risk of endometrial carcinoma among users of conjugated estrogens. $N$ Engl J Med 1975,293:1167-1170.

73. Beral V, Bull D, Reeves G. Endometrial cancer and hormone-replacement therapy in the Million Women Study. Lancet 2005,365:1543-1551. 
74. Daley AJ, Thomas A, Roalfe AK, Stokes-Lampard H, Coleman S, Rees M, et al. The effectiveness of exercise as treatment for vasomotor menopausal symptoms: randomised controlled trial. BJOG 2015,122:565-575.

75. Daley A, MacArthur C, McManus R, Stokes-Lampard H, Wilson S, Roalfe A, et al. Factors associated with the use of complementary medicine and non-pharmacological interventions in symptomatic menopausal women. Climacteric 2006,9:336-346.

76. Nonhormonal management of menopause-associated vasomotor symptoms: 2015 position statement of The North American Menopause Society. Menopause 2015,22:1155-1174.

77. MacLennan A, Lester S, Moore V. Oral oestrogen replacement therapy versus placebo for hot flushes. Cochrane Database Syst Rev 2001:CD002978.

78. Drewe J, Bucher KA, Zahner C. A systematic review of non-hormonal treatments of vasomotor symptoms in climacteric and cancer patients. Springerplus 2015,4:65.

79. MacGregor CA, Canney PA, Patterson G, McDonald R, Paul J. A randomised doubleblind controlled trial of oral soy supplements versus placebo for treatment of menopausal symptoms in patients with early breast cancer. Eur $J$ Cancer 2005,41:708-714.

80. Nikander E, Kilkkinen A, Metsa-Heikkila M, Adlercreutz H, Pietinen P, Tiitinen A, et al. A randomized placebo-controlled crossover trial with phytoestrogens in treatment of menopause in breast cancer patients. Obstet Gynecol 2003,101:1213-1220.

81. Quella SK, Loprinzi CL, Barton DL, Knost JA, Sloan JA, LaVasseur BI, et al. Evaluation of soy phytoestrogens for the treatment of hot flashes in breast cancer survivors: A North Central Cancer Treatment Group Trial. J Clin Oncol 2000,18:1068-1074.

82. Secreto G, Chiechi LM, Amadori A, Miceli R, Venturelli E, Valerio T, et al. Soy isoflavones and melatonin for the relief of climacteric symptoms: a multicenter, double-blind, randomized study. Maturitas 2004,47:11-20.

83. Nelson HD, Vesco KK, Haney E, Fu R, Nedrow A, Miller J, et al. Nonhormonal therapies for menopausal hot flashes: systematic review and meta-analysis. JAMA 2006,295:2057-2071.

84. Leach MJ, Moore V. Black cohosh (Cimicifuga spp.) for menopausal symptoms. Cochrane Database Syst Rev 2012,9:CD007244.

85. Barton DL, Loprinzi CL, Quella SK, Sloan JA, Veeder MH, Egner JR, et al. Prospective evaluation of vitamin E for hot flashes in breast cancer survivors. $J$ Clin Oncol 1998,16:495-500.

86. Ziaei S, Kazemnejad A, Zareai M. The effect of vitamin $\mathrm{E}$ on hot flashes in menopausal women. Gynecol Obstet Invest 2007,64:204-207.

87. Ramaswami R, Villarreal MD, Pitta DM, Carpenter JS, Stebbing J, Kalesan B. Venlafaxine in management of hot flashes in women with breast cancer: a systematic review and meta-analysis. Breast Cancer Res Treat 2015,152:231-237.

88. Spina E, Santoro V, D'Arrigo C. Clinically relevant pharmacokinetic drug interactions with second-generation antidepressants: an update. Clin Ther 2008,30:1206-1227.

89. Caraci F, Crupi R, Drago F, Spina E. Metabolic drug interactions between antidepressants and anticancer drugs: focus on selective serotonin reuptake inhibitors and hypericum extract. Curr Drug Metab 2011,12:570-577.

90. Boekhout AH, Vincent AD, Dalesio OB, van den Bosch J, Foekema-Tons JH, Adriaansz S, et al. Management of hot flashes in patients who have breast cancer with venlafaxine and clonidine: a randomized, double-blind, placebo-controlled trial. $J$ Clin Oncol 2011,29:3862-3868. 
91. Joffe H, Guthrie KA, LaCroix AZ, Reed SD, Ensrud KE, Manson JE, et al. Low-dose estradiol and the serotonin-norepinephrine reuptake inhibitor venlafaxine for vasomotor symptoms: a randomized clinical trial. JAMA Intern Med 2014,174:10581066.

92. Pandya KJ, Morrow GR, Roscoe JA, Zhao H, Hickok JT, Pajon E, et al. Gabapentin for hot flashes in 420 women with breast cancer: a randomised double-blind placebocontrolled trial. Lancet 2005,366:818-824.

93. Guttuso T, Jr., Kurlan R, McDermott MP, Kieburtz K. Gabapentin's effects on hot flashes in postmenopausal women: a randomized controlled trial. Obstet Gynecol 2003,101:337-345.

94. Daley AJ, Stokes-Lampard HJ, Macarthur C. Exercise to reduce vasomotor and other menopausal symptoms: a review. Maturitas 2009,63:176-180.

95. Teoman N, Ozcan A, Acar B. The effect of exercise on physical fitness and quality of life in postmenopausal women. Maturitas 2004,47:71-77.

96. Winters-Stone KM, Dobek J, Nail LM, Bennett JA, Leo MC, Torgrimson-Ojerio B, et al. Impact + resistance training improves bone health and body composition in prematurely menopausal breast cancer survivors: a randomized controlled trial. Osteoporos Int 2013,24:1637-1646.

97. Everhov AH, Nyberg T, Bergmark K, Citarella A, Radestad AF, Hirschberg AL, et al. Hormone therapy after uterine cervical cancer treatment: a Swedish population-based study. Menopause 2015,22:633-639.

98. Chlebowski RT, Hendrix SL, Langer RD, Stefanick ML, Gass M, Lane D, et al. Influence of estrogen plus progestin on breast cancer and mammography in healthy postmenopausal women: the Women's Health Initiative Randomized Trial. JAMA 2003,289:3243-3253.

99. Schierbeck LL, Rejnmark L, Tofteng CL, Stilgren L, Eiken P, Mosekilde L, et al. Effect of hormone replacement therapy on cardiovascular events in recently postmenopausal women: randomised trial. BMJ 2012,345:e6409.

100. Schonberg MA, Davis RB, Wee CC. After the Women's Health Initiative: decision making and trust of women taking hormone therapy. Womens Health Issues 2005,15:187-195.

101. Sawka AM, Huh A, Dolovich L, Papaioannou A, Eva K, Thabane L, et al. Attitudes of women who are currently using or recently stopped estrogen replacement therapy with or without progestins: results of the AWARE survey. J Obstet Gynaecol Can 2004,26:967-973.

102. Pitkin J, Rees MC, Gray S, Lumsden MA, Marsden J, Stevenson JC, et al. Management of premature menopause. Menopause Int 2007,13:44-45.

103. Pettersson F, Ryberg M, Malker B. Second primary cancer after treatment of invasive carcinoma of the uterine cervix, compared with those arising after treatment for in situ carcinomas. An effect of irradiation? A cancer registry study. Acta Obstet Gynecol Scand 1990,69:161-174.

104. Kapp DS, Fischer D, Grady KJ, Schwartz PE. Subsequent malignancies associated with carcinoma of the uterine cervix: including an analysis of the effect of patient and treatment parameters on incidence and sites of metachronous malignancies. Int $J$ Radiat Oncol Biol Phys 1982,8:197-205.

105. Wright JD, St Clair CM, Deutsch I, Burke WM, Gorrochurn P, Sun X, et al. Pelvic radiotherapy and the risk of secondary leukemia and multiple myeloma. Cancer 2010,116:2486-2492. 
106. Boice JD, Jr., Day NE, Andersen A, Brinton LA, Brown R, Choi NW, et al. Second cancers following radiation treatment for cervical cancer. An international collaboration among cancer registries. J Natl Cancer Inst 1985,74:955-975.

107. Rodriguez AM, Kuo YF, Goodwin JS. Risk of colorectal cancer among long-term cervical cancer survivors. Med Oncol 2014,31:943.

108. Kumar S, Shah JP, Bryant CS, Seward S, Ali-Fehmi R, Morris RT, et al. Radiationassociated endometrial cancer. Obstet Gynecol 2009,113:319-325.

109. Macara LM, Lamont D, Symonds RP. Second malignancies in cervical cancer patients in the west of Scotland. Scott Med J 1998,43:16-18. 